\title{
Extreme winds over Europe in the ENSEMBLES regional climate models
}

\author{
S. D. Outten and I. Esau \\ Nansen Environmental and Remote Sensing Center, Thormhlensgt. 47, 5006 Bergen, Norway
}

Correspondence to: S. D. Outten (stephen.outten@nersc.no)

Received: 2 November 2012 - Published in Atmos. Chem. Phys. Discuss.: 10 January 2013

Revised: 26 April 2013 - Accepted: 29 April 2013 - Published: 22 May 2013

\begin{abstract}
Extreme winds cause vast amounts of damage every year and represent a major concern for numerous industries including construction, afforestation, wind energy and many others. Under a changing climate, the intensity and frequency of extreme events are expected to change, and accurate projections of these changes will be invaluable to decision makers and society as a whole. This work examines four regional climate model downscalings over Europe following the SRES A1B scenario from the "ENSEMBLE-based Predictions of Climate Changes and their Impacts" project (ENSEMBLES). It investigates the projected changes in the $50 \mathrm{yr}$ return wind speeds and the associated uncertainties. This is accomplished by employing the peaks-over-threshold method with the use of the generalised Pareto distribution. The models show that, for much of Europe, the $50 \mathrm{yr}$ return wind is projected to change by less than $2 \mathrm{~m} \mathrm{~s}^{-1}$, while the uncertainties associated with the statistical estimates are larger than this. In keeping with previous works in this field, the largest source of uncertainty is found to be the intermodel spread, with some locations showing differences in the $50 \mathrm{yr}$ return wind of over $20 \mathrm{~m} \mathrm{~s}^{-1}$ between two different downscalings.
\end{abstract}

\section{Introduction}

The case for anthropogenically forced climate change is now well established and it represents one of the most serious concerns currently facing mankind. The last report from the Intergovernmental Panel on Climate Change (IPCC) concluded that greenhouse gas forcing has very likely caused most of the observed global warming over the last $50 \mathrm{yr}$ (Solomon et al., 2007). While this represents a significant risk on its own, the impact of large-scale climate change will be felt most strongly on the local scale through the changes to the frequency and intensity of extreme events (Beniston et al., 2007). Europe has witnessed the impacts of extreme temperatures during the heat waves of 2003 and 2010 (Beniston, 2004; Grumm, 2011; Robine et al., 2008), and during the European cold wave of 2012 (WMO, 2012). While such events often result in a great loss of life, far more economic damage is done each year by extreme winds. The international reinsurance group, Munich RE, estimates that on average $76 \%$ of insured losses every year are due to extreme winds (Munich RE, 2011). Good knowledge of extreme winds at a given site is also vital for the safe design and construction of exposed structures, for example, bridges, wind turbines, etc. Furthermore, such information also plays an important role in planning for the development of planted forests, since growth and survival rates are limited by the physiological and mechanical effects of the wind (Quine, 2000), and in the planning of future wind farm placements, since all turbines have a cut-out speed above which they cannot operate and a survival speed above which they cannot operate. With the damage from extreme winds rising each year (Munich RE, 2011) and wind power providing an ever greater proportion of the world's power, good projections of extreme winds will be increasingly important over the coming decades.

A climatology of extreme winds and their return periods over Europe for the last half of the 20th century was established by Della Marta et al. (2009) by applying an extreme value analysis to the European Centre for Medium-Range Weather Forecasts (ECMWF) ERA-40 reanalysis. Donat et al. (2011b) and Wang et al. (2011) both examined trends in extreme winds over the last century. Wang et al. (2011) derived these trends from geostrophic wind speeds calculated 
from pressure measurements at stations across Europe, while Donat et al. (2011b) examined the 95th percentile of daily maximum wind speeds in the NOAA 20th century reanalysis. Both found a positive trend over much of Northern Europe, which increased over the last $30 \mathrm{yr}$. Zwiers and Kharin (1998) made use of climate model projections to investigate estimates of extreme winds for the future. They showed an increase in extreme winds over Northern Europe projected by the Canadian Global Climate Model (GCM) under a doubling $\mathrm{CO}_{2}$ scenario.

In recent years, investigations have focussed on the future projections from regional climate models (RCMs). Beniston et al. (2007), Schwierz et al. (2010), and Rockel and Woth (2007) all examined extreme winds in the regional downscalings of the Prediction of Regional Scenarios and Uncertainties for Defining European Climate Change Risks and Effects (PRUDENCE, EU FP5 project) project. The three studies identified extreme winds as the 90th, 98th and 99th percentiles of wind speeds respectively and all three showed similar projected changes between the periods of 1961-1990 and 2071-2100: an increase in extreme winds over the North Sea, Northern Europe and UK combined with a decrease in extreme winds over the Mediterranean Sea and Northern Scandinavia. Donat et al. (2011a) and Pryor et al. (2012a) both investigated extreme winds in the downscalings from the Ensemble-Based Predictions of Climate Changes and their Impacts (ENSEMBLES, EU FP6 project) project (the successor to PRUDENCE). Donat et al. (2011a) found an increase in the 98th percentile of wind speeds over the North Sea and Northern Europe, with an associated decrease over the Mediterranean Sea. The largest changes in both cases were identified over the sea, while over the continent they classified the projected changes in the individual downscalings as 'spotty' and non-consistent. Pryor et al. (2012a) investigated changes in the $50 \mathrm{yr}$ return wind speed and again found increases over the North Sea and Northern Europe. Unfortunately, their study domain only covered Northern Europe and Scandinavia, so a comparison of the results over the Mediterranean Sea is not possible. However, they did identify that the $50 \mathrm{yr}$ return wind was not projected to evolve out of the historic envelope until the end of the 21 st century. Nikulin et al. (2011) examined the change in $20 \mathrm{yr}$ return wind speeds from a single RCM over the whole of Europe and identified some areas of increase and some of decrease over the Mediterranean. Of the studies discussed here examining future projections from climate models, only the works of Pryor et al. (2012a) and Nikulin et al. (2011) employed extreme value analysis for the study of extreme wind speeds.

There are numerous challenges with the projection and investigation of extreme wind events under climate change. First, since turbulent energy cascades from larger scales to smaller scales, extreme winds are a local-scale effect; therefore, their study in models necessitates the fine-scale horizontal resolution found in RCMs. RCMs provide highresolution output that is more suitable than global climate model output for use in impact studies, which are of great interest to society, making them a very useful tool. The higher spatial resolution of RCMs allows for improved description of orographic effects, land-sea contrasts, and sea ice edges. Perhaps most important, RCMs can and do have improved representation of the physical and dynamical process of the climate system compared to global climate models. This is due to the combination of high temporal and spatial resolution. These models do however have some weaknesses, including their dependence on the quality of the global model data that is used to drive them, and the various issues with their own model physics. A recent review of the state of regional climate models is given in Rummukainen (2010), but crucially it has been shown that RCMs tend to underestimate wind speeds when compared to observations (Kunz et al., 2010). However, regional climate models are near the end of a long chain of projections, for example, socio-economic assumptions, projected emissions scenarios, carbon cycle response and concentration projections, global climate sensitivity estimates, regional climate simulations, and lastly, the estimation of possible impacts (Jones, 2000). Each stage of this chain introduces further uncertainties into the final projection from the RCM (Foley, 2010). In an attempt to put the extreme wind estimates from this work into context of some of these uncertainties, estimates will be made for multiple simulations and their differences and uncertainties will be discussed.

The second major challenge in investigating extreme winds under a changing climate comes from the need to employ appropriate statistical techniques both to describe the events and to identify their change in frequency. A review of methods used to calculate extreme winds is given by $\mathrm{Pa}-$ lutikof et al. (1999). A number of works have employed the Weibull method - this assumes the wind speeds can be fitted to a Weibull distribution and extreme events are then obtained by extrapolation (e.g. Quine, 2000; Lun and Lam, 2000; Koh et al., 2011). This method relies on a distribution that is well fitted to the non-extreme events that make up the largest proportion of the data. The Weibull method also does not provide analytical confidence intervals for the estimated return values (Perrin, 2006).

Alternative approaches come from extreme value theory: a branch of mathematics that deals with extreme distributions and determining the probability of an event occurring that is more extreme than any previously observed. In general terms there are two main approaches based on the two main theorems. The block maxima method, based on Fisher-Tippett theorem that states that the maxima of multiple samples (blocks) of independent, identically distributed data will converge to one of three classic distributions: the Gumbel, the Fréchet, or the Weibull distribution (Fisher and Tippett, 1928; Gumbel, 1958). These three distributions can be grouped into one family and described by the single generalised extreme value (GEV) distribution. A serious criticism of the block maxima method is that it only considers a single 
value from each block. This greatly reduces the amount of data available for analysis, and ignores sub-block events, since only the largest event in any block is included.

The second approach of extreme value theory is the peaksover-threshold (POT) method. This is based on the PickandsBalkema-de Haan theorem which states that the distribution of exceedances over a sufficiently high threshold will converge to a generalised Pareto distribution (GPD) (Balkema and de Hann, 1974; Pickands, 1975). The POT method has the advantage over the block maxima method that it extracts a larger number of extreme values, thereby increasing the sample size and decreasing the sampling uncertainty. A more detailed introduction to both of these methods, and the theorems they are based upon, can be found in Coles (2001), and in references therein.

The POT method was chosen for this work due to its decreased uncertainties compared to the block-maxima method and its focus on extreme events compared to the Weibull method. It is used to examine the $50 \mathrm{yr}$ return value of the $10 \mathrm{~m}$ winds $\left(U_{50}\right)$ in four RCM downscalings over Europe for a recent and a future period. The geographical distributions of projected changes in $U_{50}$ are shown, and these projected changes are compared to the uncertainty associated with their derivation. Section 2 details the data sources, while Sect. 3 details the statistical methods employed. The results are shown in Sect. 4; a discussion and conclusions given in Sect. 5.

\section{Source data}

The data used in this project comes from the RCM simulations conducted as part of the ENSEMBLES project (van der Linden and Mitchell, 2009). The ENSEMBLES project created a matrix of experiments in which a range of GCMs were downscaled using various RCMs. This work uses the data from four of these downscalings where two GCMs were each downscaled by two different institutes, each using their own RCM (Table 1). The GCMs used were the Bergen Climate Model (BCM) (Furevik et al., 2003) and European Centre Hamburg Model version 5 coupled with the Max Planck Institute Ocean Model (ECHAM5/MPI-OM) (Roeckner et al., 2003; Marsland et al., 2003), while the RCMs used were the Rossby Centre Atmosphere climate model (RCA3) at the Swedish Meteorological and Hydrological Institute (Samuelsson et al., 2011), and the HIRHAM regional climate model version 5 at the Danish Meteorological Institute (Christensen et al., 2006). The HIRHAM acronym is a combination of the HIRLAM (High Resolution Limited Area Model) and ECHAM (European Centre Hamburg Model), since HIRHAM combines dynamics from these two models.

The RCM simulations all used the same domain covering Europe and had a horizontal grid spacing of $25 \mathrm{~km}$. This work examines the daily model output for two $30 \mathrm{yr}$ periods: 1961-1990 (reference) and 2070-2099 (future). The length of the periods was chosen to be $30 \mathrm{yr}$ so as to provide sufficient data to determine $50 \mathrm{yr}$ return events. The reference period has been commonly used in previous works (e.g. Beniston et al., 2007; Schwierz et al., 2010; Rockel and Woth, 2007 , etc.) and was selected so as to provide maximum compatibility. The simulations of the future period were all forced with the SRES A1B scenario; a mid-range scenario in terms of global warming at the end of the 21 st century (Nakicenovic and Swart, 2000).

While extreme wind speed calculations are often based on hourly, three-hourly, or six-hourly instantaneous data from models, this disjunct sampling does lead to an underestimation of the extreme winds due to the missed peak events that occur between the sampling times. Larsen and Mann (2006) demonstrated that taking hourly samples of ten-minute winds results in an underestimation of the extreme events by approximately $5 \%$, while for $6 \mathrm{~h}$ sampling this becomes approximately $15 \%$. This work examines the daily maximum $10 \mathrm{~m}$ wind speed, which is the highest $10 \mathrm{~m}$ wind speed at any given time step during each day, thereby ensuring that all peak events are captured and avoiding the problem of disjunct sampling. A similar relationship has been found for the horizontal resolution of the model domain and the magnitude of the extreme wind speeds. Pryor et al. (2012b) identified that changing the model domain from a resolution of $50 \mathrm{~km}$ to a resolution of $6 \mathrm{~km}$ resulted in only a $5 \%$ change in the mean $10 \mathrm{~m}$ wind speed, but with a change of over $10 \%$ seen in the extreme winds.

\section{Methods}

In accordance with the Pickands-Balkema-de Haan theorem, the exceedances over a given threshold need to be determined once a suitable threshold has been selected. If the threshold is too high, very few exceedances will exist, leading to increased variance in the parameter estimation. Conversely, if the threshold is too low, the exceedances cannot be considered extreme events, and the GPD fit will no longer be appropriate, which results in a bias being introduced (Van de Vyver and Delcloo, 2011). One commonly used approach for determining a suitable threshold is to examine by eye plots of the sample mean excess (SME) for a range of thresholds (e.g. Supplement Fig. S1). The SME is the sum of the excesses above the threshold divided by the number of data points which exceeded the threshold. At high thresholds, the SME fluctuates, while at low thresholds the SME increases. Between these two cases, the SME is stable as a balance is achieved between the bias and the variance. The lowest threshold within this stable region is usually selected and used for the POT method.

The aim in this work was to create maps of return events based on the model domain. The problem is that there is no clear methodology to automate the threshold selection process which could handle the various wind regimes without 
Table 1. The driving global model for each simulation is given in the first column. The regional climate model used and the institute who performed the downscaling are given in second and third column, respectively. The fourth column shows the abbreviation that is used in this paper for each of the simulations, while the fifth column gives the horizontal resolution of the RCM. The final column provides a reference where full details of the RCMs can be found.

\begin{tabular}{llllll}
\hline $\begin{array}{l}\text { Global climate } \\
\text { model }\end{array}$ & $\begin{array}{l}\text { Regional climate } \\
\text { model }\end{array}$ & Institute & Abbreviation & Resolution & Reference \\
\hline $\begin{array}{l}\text { Bergen Climate } \\
\text { Model }\end{array}$ & HIRHAM5 & $\begin{array}{l}\text { Danish Meteorological } \\
\text { Institute }\end{array}$ & BCM-HIRHAM5 & $25 \mathrm{~km}$ & Christensen et al. (2006) \\
& RCA3 & $\begin{array}{l}\text { Swedish Meteorological and } \\
\text { Hydrological Institute } \\
\text { Danish Meteorological } \\
\text { Institute }\end{array}$ & BCM-RCA3 & 25 km & Samuelsson et al. (2011) \\
& HIRHAM5 & $\begin{array}{l}\text { Swish Meteorological and } \\
\text { Hydrological Institute }\end{array}$ & ECHAM5-RCA3 & $25 \mathrm{~km}$ & Samuelsson et al. (2011) \\
& RCA3 & & & & \\
\hline
\end{tabular}

introducing a large number of errors, and any such process would be computationally demanding to implement. For this reason, a simpler approach was employed. The threshold was selected as the lowest of the annual maxima at each grid point. While this approach guaranteed a minimum of $30 \mathrm{ex}-$ ceedances for each of the $30 \mathrm{yr}$ samples, it yielded between approximately 50 and 300 exceedances, representing the top $0.5 \%$ to $2.7 \%$ of wind events at each grid point. A number of locations were selected based on the different wind regimes they had, and the thresholds derived by using our approach were compared with those derived by examining the SME plot. This provided confidence for the threshold selection method used. Furthermore, the quality of the GPD fits based on the derived thresholds was also assessed at these locations, by using quantile-quantile plots and by comparing the cumulative distribution function plot to the empirical distribution (e.g. Supplement Fig. S2). The high quality of these fits provided further confidence that the thresholds were suitable.

Once the exceedances over the threshold were obtained, a simple declustering method was employed to ensure the independent nature of the extremes, as required by the POT approach. This method identified peak exceedances and removed exceedances that occurred on the adjacent days. Since the data was daily maximum values, it was possible for two consecutive exceedances to be only a time step apart if the first occurred at the end of a day and the second occurred at the beginning of the next day. The declustering meant that there was at least $24 \mathrm{~h}$ between any two exceedances, thereby ensuring their independence.

A maximum likelihood estimation method was used to fit a GPD to the resulting exceedances. This was accomplished by minimising the negative log-likelihood with respect to the parameters of the GPD. The Nelder-Mead simplex direct search algorithm was chosen for this task since it is a robust method for minimising an objective function in a multi-dimensional space (Lagarias et al., 1998). The GPD was then used to estimate $U_{50}$. To determine confi- dence intervals on this estimate, a region of parameter space was defined based on the $95 \%$ level of log-likelihood using a Chi squared distribution. A trust-region-reflective optimisation algorithm was used to numerically find the range of $U_{50}$ that occurred within the parameter space region. This approach differs from that of Pryor et al. (2012a), where the extreme return wind speed estimates are assumed to have a Gaussian distribution, in that it accounts for the nonlinearity of the parameter space in deriving the confidence intervals. This method also produces larger confidence intervals than the bootstrapping approach used by Naess and Gaidai (2009), demonstrating the sensitivity of the generalised Pareto distribution to the shape parameter. In applying this methodology to the two $30 \mathrm{yr}$ periods of extremes, it is assumed that the climate is stationary within each period. The equations for the generalised Pareto distribution are given in Appendix A and a more comprehensive introduction to the methods employed in this work is given in Coles (2001).

The final methodology was therefore as follows:

- Extract the $30 \mathrm{yr}$ time series of daily maximum winds at a grid point in the reference period.

- Determine the annual maxima and set the lowest as the threshold.

- Extract the exceedances above this threshold from the time series.

- Apply a simple declustering method to isolate individual events.

- Use a maximum likelihood estimation method to determine the parameters of the GPD fit.

- Calculate $U_{50}$ based on this GPD fit.

- Use the $95 \%$ level of the chi-squared distribution of likelihood to derive confidence intervals in a profile likelihood approach. 

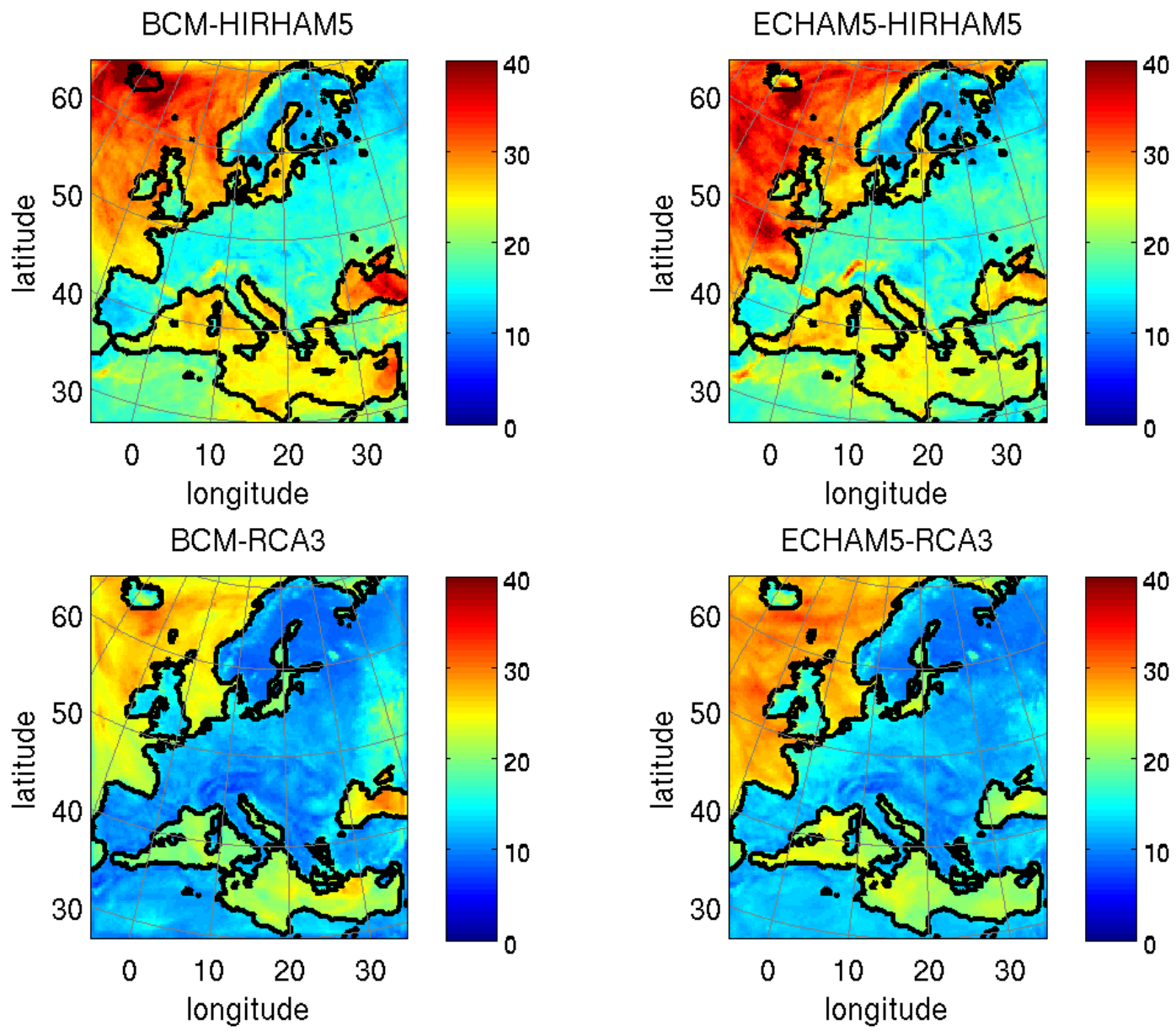

Fig. 1. The $50 \mathrm{yr}$ return $10 \mathrm{~m}$ wind speed in $\mathrm{m} \mathrm{s}^{-1}$ calculated using the GPD for four different downscalings, with red/blue colours representing high and low return wind speeds, respectively. The columns are using the Bergen Climate Model (left), and the ECHAM5 global climate model (right); while the rows are the HIRHAM5 (top) and the RCA3 (bottom) regional climate models.

- Repeat for every grid point in all four downscaling experiments.

- Repeat for the future period.

\section{Extreme winds over Europe}

The $50 \mathrm{yr}$ winds show some clear differences between the four downscalings (Fig. 1). The most pronounced of which is that the return winds from the RCA3 downscalings are approximately $5 \mathrm{~m} \mathrm{~s}^{-1}$ lower than those from the HIRHAM5 downscalings. At some locations, this difference rises to over $20 \mathrm{~m} \mathrm{~s}^{-1}$. Pryor et al. (2012a) identified that downscalings of ECHAM5 and ERA-40 reanalysis data produced very similar results when using HIRHAM5, but that downscalings using RCA3 showed a consistent negative bias in $U_{50}$ compared to reanalysis, as previously identified by Höglund et al. (2009). A report by SMHI on this issue speculated that this was due in part to a poorly chosen roughness length within the planetary boundary layer scheme of RCA3 (Höglund et al., 2009).
The difference depending upon which GCM is downscaled is less striking, with downscalings of ECHAM5 producing return wind speeds $0.5-1 \mathrm{~m} \mathrm{~s}^{-1}$ higher on average than those produced using the BCM. There are also differences in the distribution of $U_{50}$ depending upon the GCM downscaled; with ECHAM5 producing higher wind speeds over the North Atlantic, and yet lower wind speeds over the Black Sea. Intermodel spread has already been identified as the main source of uncertainty in estimating return values from climate models (Kharin et al., 2007); however, Fig. 1 suggests that it is the spread between different RCMs that is most important when considering extreme winds.

Despite the differences, there are some obvious common features between the four downscalings: the highest return wind speeds appear off the south east coast of Iceland where corner jets are frequent; high $U_{50}$ over the eastern end of the Black Sea, near the Kaçkar mountains of Turkey and the Caucasus range in Georgia; increased wind speeds extend over the mountains of Norway; and isolated strips of locally higher $U_{50}$ are seen over the Atlas mountains in Morocco, 

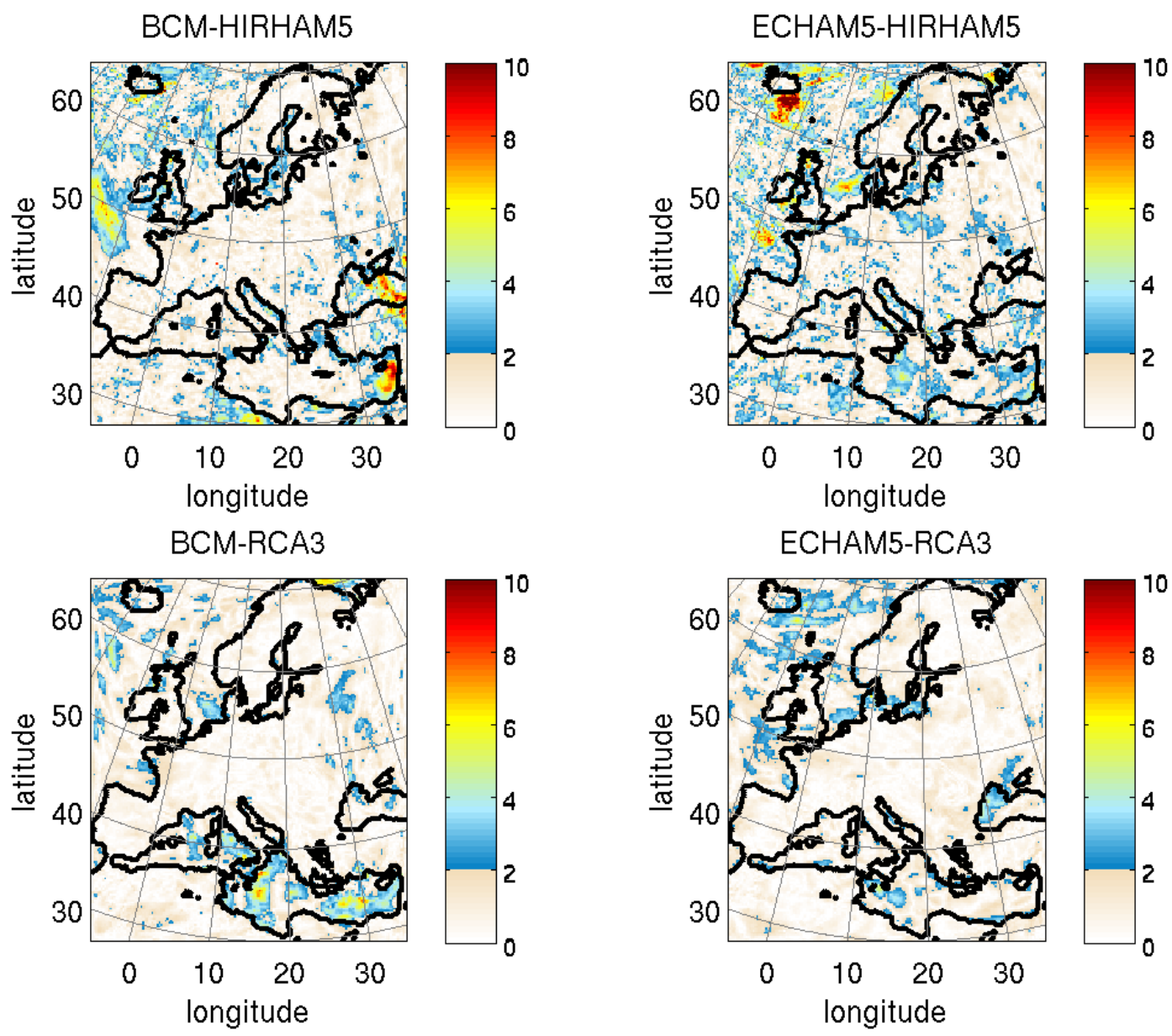

Fig. 2. The magnitude of the change in $50 \mathrm{yr}$ return $10 \mathrm{~m}$ wind speed between the reference $30 \mathrm{yr}$ period (1961-1990), and the future $30 \mathrm{yr}$ period (2070-2099). The estimates are in in $\mathrm{m} \mathrm{s}^{-1}$ and show the results for the four different downscalings. The beige regions indicate locations where the projected changes in the $50 \mathrm{yr}$ return $10 \mathrm{~m}$ wind speeds of $2 \mathrm{~m} \mathrm{~s}^{-1}$ or less, while the blue to red regions indicate those locations with $50 \mathrm{yr}$ winds between 2 and $10 \mathrm{~m} \mathrm{~s}^{-1}$.

the Pyrenees mountains between France and Spain, and the Alps on the borders of France, Switzerland and Italy. This highlights the strong connection between extreme winds and orography, as previous studies have investigated (Outten et al., 2009; Renfrew et al., 2009; Smith, 1982). While the high $U_{50}$ locations over land are less apparent in the RCA3 downscalings, they do perhaps possess a more interesting feature. The peak $U_{50}$ is comparable to the continental average, and is only identifiable due to the lower than average $U_{50}$ around it. For example, in BCM-RCA3, the mean $U_{50}$ over Western Europe is approximately $10.7 \mathrm{~m} \mathrm{~s}^{-1}$, the mean $U_{50}$ in the strip over the Alps $\left(45.8^{\circ} \mathrm{N}, 7.4^{\circ} \mathrm{W}\right)$ is $10.8 \mathrm{~m} \mathrm{~s}^{-1}$, but the mean $U_{50}$ either side of the strip over the Alps is $7.2 \mathrm{~m} \mathrm{~s}^{-1}$. This is also visible for the Atlas Mountains, the Pyrenees, and the mountains of Norway; and this feature remains unexplained.

Comparing the changes in $U_{50}$ between the reference period and the future period (Fig. 2), it is clear that at most locations the change is less than $2 \mathrm{~m} \mathrm{~s}^{-1}$ in all four downscal- ings, as indicated by the light beige regions. This is similar to the findings of Nikulin et al. (2011) and Pryor et al. (2012a). Also similar to their works, the downscalings presented here show little agreement in either the location or magnitude of changes greater than $2 \mathrm{~m} \mathrm{~s}^{-1}$. For example, the HIRHAM5 downscaling of the BCM shows regions of high change located in the mid-latitudes of the eastern Atlantic, the eastern half of the Black Sea, off the coast of Lebanon and Syria, and over northern Libya, while the RCA3 downscaling of the same GCM shows none of these locations as having significant change. It instead shows larger changes centred over the eastern and central Mediterranean.

Figure 3 shows the confidence intervals at the $95 \%$ level for the estimates of the return wind speed in the reference period shown in Fig. 2. Comparing these to the plots of future change it can be seen that at almost all locations, any change projected by any of the models is comparable to, or more often smaller than, the uncertainty associated with the estimate of the return wind speeds. Hence the signal of changes 

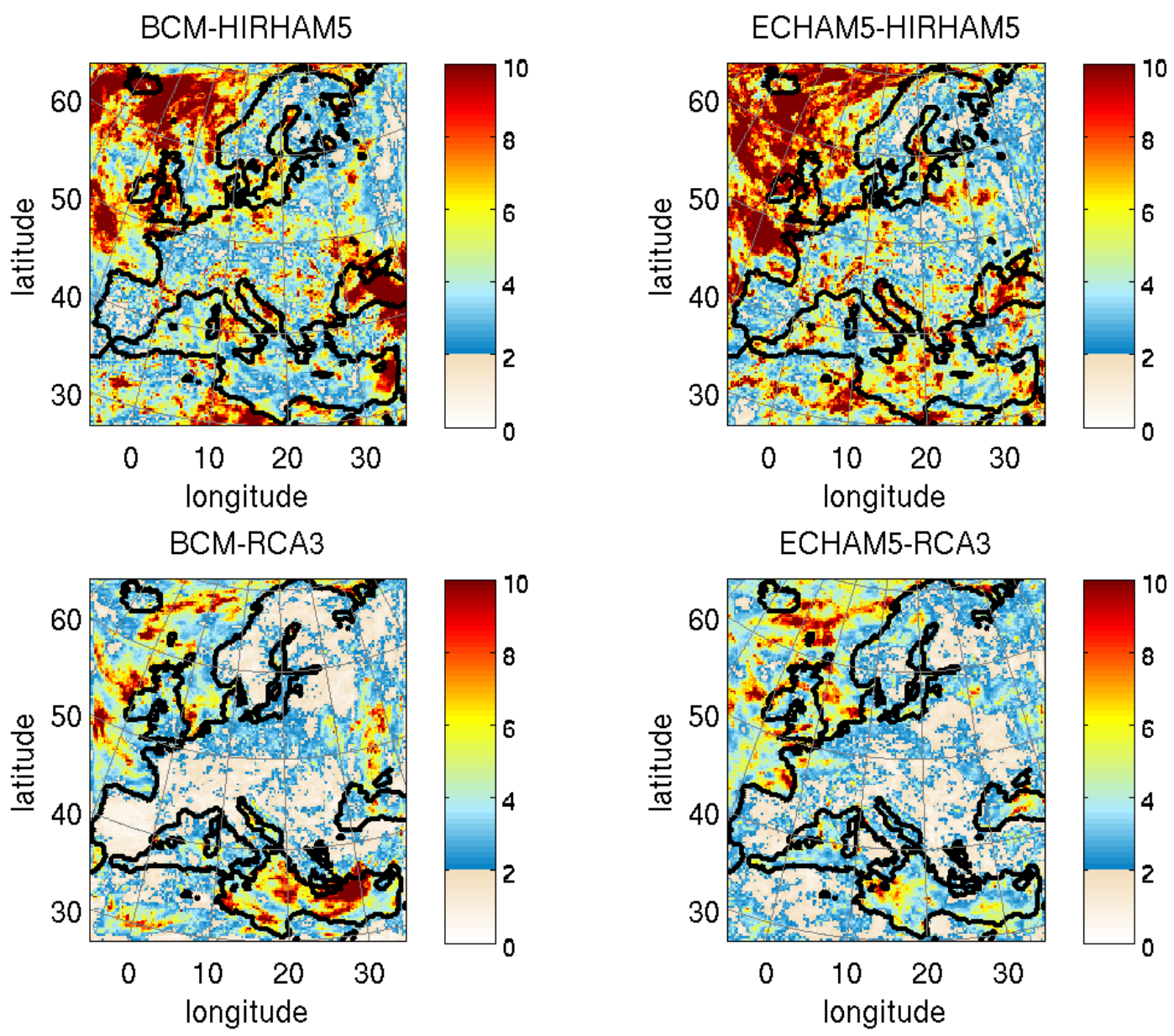

Fig. 3. The magnitude of the confidence interval associated with the maximum likelihood estimate of the $50 \mathrm{yr}$ return wind speed in the reference period. These are shown in $\mathrm{m} \mathrm{s}^{-1}$ and are plotted on the same colour scale as the $50 \mathrm{yr}$ return estimates in Fig. 2 . The plots show the results for the four different downscalings. The beige regions indicate locations where the confidence intervals are $2 \mathrm{~m} \mathrm{~s}^{-1}$ or less, while the blue to red regions indicate those locations with $50 \mathrm{yr}$ winds between 2 and $10 \mathrm{~m} \mathrm{~s}^{-1}$.

in extreme winds projected in these RCM downscalings is indistinguishable from the noise associated with the uncertainties of estimating a $50 \mathrm{yr}$ event. While the locations of highest uncertainty differ from downscaling to downscaling, they do correspond to the location of high return wind speed within each downscaling. It should also be noted that the confidence intervals are not evenly distributed around the maximum likelihood estimation (MLE). The upper limit of the confidence interval is invariably much further from the MLE than the lower limit (e.g. Supplement Fig. S2: profile likelihood). This is different from some works in which the confidence intervals are considerably smaller due to the assumption that they follow a Gaussian distribution (e.g. Pryor et al., 2012a).

One region of particular interest in recent studies of extreme winds has been the North Sea, especially between Belgium and the UK As stated earlier, many previous studies have suggested an increase in the wind speed in this region, both in future projections from climate models and in historical reanalyses (Beniston et al., 2007; Schwierz et al., 2010; Rockel and Woth 2007; Wang et al., 2011; Donat et al., 2011b). The four downscalings presented here all show different changes in this region, ranging from approximately $1 \mathrm{~m} \mathrm{~s}^{-1}$ to $8 \mathrm{~m} \mathrm{~s}^{-1}$. The only significant change is shown by the HIRHAM5 downscaling of ECHAM5, which shows a peak future change in $U_{50}$ of $8.2 \mathrm{~m} \mathrm{~s}^{-1}$, with a confidence interval of $3.6 \mathrm{~m} \mathrm{~s}^{-1}$. It is one of the few locations where the projected change is greater than the uncertainty. Pryor et al. (2012a) also found an increase in $U_{50}$ in this location in the HIRHAM5 downscaling of ECHAM5, with no increase projected by the equivalent RCA3 downscaling. In contrast, Van den Eynde et al. (2012) examined operation model wind fields from the Norwegian Meteorological Institute for this region covering the period of 1955 to 2006 and they found no significant trends in either the mean or extreme winds. One possible explanation for this discrepancy is the seasonality in the trends in the Southern North Sea, as identified 
by Wang et al. (2011). While this could be examined in the downscalings, it is beyond the scope of this work.

\section{Discussion and Conclusions}

This work has examined the $50 \mathrm{yr}$ return $10 \mathrm{~m}$ wind speeds over Europe in four different downscalings based on the peaks over threshold method and using the generalised Pareto distribution. For most locations over Europe the different downscalings all suggest a change in $U_{50}$ of around $1-2 \mathrm{~m} \mathrm{~s}^{-1}$ in keeping with previous research (Pryor et al., 2012a; Nikulin et al., 2011). While the downscalings show some isolated areas where there is a greater change projected in $U_{50}$, they do not agree on the location of these areas or the magnitude of the change. Indeed the inter-model spread, especially between different RCMs, appears to be the largest source of uncertainty.

Another source of uncertainty comes from the statistical estimation of a $50 \mathrm{yr}$ event based on $30 \mathrm{yr}$ of data. The average change in $U_{50}$ in the HIRHAM (RCA3) downscalings was approximately $1.13 \mathrm{~m} \mathrm{~s}^{-1}$ and $1.8 \mathrm{~m} \mathrm{~s}^{-1}\left(0.69 \mathrm{~m} \mathrm{~s}^{-1}\right.$ and $1.40 \mathrm{~m} \mathrm{~s}^{-1}$ ) over the land and sea, respectively, compared to the average confidence intervals of $4.39 \mathrm{~m} \mathrm{~s}^{-1}$ and $6.93 \mathrm{~m} \mathrm{~s}^{-1}\left(2.57 \mathrm{~m} \mathrm{~s}^{-1}\right.$ and $\left.4.59 \mathrm{~m} \mathrm{~s}^{-1}\right)$ respectively. Therefore, the changes projected by these models in the $50 \mathrm{yr}$ return wind speed are well within the uncertainties of those projections. Since this source of uncertainty stems from the method used, other methods were also considered. The annual-maxima method was employed, resulting in a Generalised Extreme Value distribution; however, since a $30 \mathrm{yr}$ sample only provides 30 maxima, the uncertainties were considerably larger. Other works have made use of the Gumbel distribution (e.g. Pryor et al., 2012a). This is based on a modification of the block-maxima approach, where a likelihood ratio test is used to show that the two parameter Gumbel distribution provides an equally valid fit to the data as does the three parameter GEV. By reducing the problem to a Gumbel distribution, the shape parameter to which the confidence intervals are so sensitive is removed, thereby reducing the uncertainty. When this method was applied in this work it was found that a considerable area of the domain failed the likelihood ratio test in either the current or future period (Supplement Fig. S3). This area was different in each model, making it an unviable method to use for intercomparison.

Given the value of good knowledge of extreme wind speeds to so many sectors, for example, reinsurance, construction, wind energy, forestry planning, high-speed rails, etc., it will become increasingly important to be able to accurately estimate both the return levels of wind speeds and the uncertainties associated with those estimates. While new techniques are being developed to improve the statistical tools (e.g. new estimator techniques for the shape parameter; Van de Vyver and Delcloo, 2011), the issue of inter-model spread in the RCMs remains a major problem. It is also im- portant to state that this study has not addressed the attribution of the projected changes in extreme winds to either changes in anthropogenic forcing or natural variability.

\section{Appendix A}

\section{Generalised Pareto distribution}

The approach used in this paper is a peaks-over-threshold (POT), extreme value method, thus it treats those values that exceed a given threshold, $u$, as being extremes. Like many such methods, it assumes that the values are independent and identically distributed (i.i.d.) in time (i.e. the values have no correlation or clustering). The second theorem of extreme value theory, or Pickands-Balkema-De Haan theorem, states that the magnitude of these exceedances can be approximated by a generalised Pareto distribution (GPD) and their frequencies by a Poisson distribution. The following is based on Coles (2001) and a more complete introduction to extreme value analysis is given therein.

Let $X=\left\{X_{1}, X_{2}, \ldots X_{n}\right\}$ be a random sample of an i.i.d. series with common distribution function $F$. The distribution of extreme events in the sample, defined as those exceeding the threshold $u$, is given by the conditional probability:

$$
P\{X>u+y \mid X>u\}=\frac{1-F(u+y)}{1-F(u)}, \quad y>0 .
$$

Using a sufficiently high threshold, this distribution function converges to the generalised Pareto distribution as $n \rightarrow \infty$. The cumulative distribution function for the GPD is given by

$$
H(y)= \begin{cases}1-\left(1+\frac{\xi y}{\sigma}\right)^{-1 / \xi}, & \xi \neq 0 \\ 1-e^{-y / \sigma}, & \xi \neq 0,\end{cases}
$$

where $\xi$ is the shape parameter and $\sigma$ is the scale parameter. The GPD corresponds to the exponential, ordinary Pareto, and Pareto II type distributions when $\xi=0, \xi<0$ and $\xi>0$, respectively.

For a suitably chosen threshold, the number of exceedances can be assumed to approximate a Poisson distribution with parameter $\lambda$. This parameter gives the average rate of exceedances per year. The $T$ year return event, $U_{T}$, is an event (or quantile) which on average is only exceeded once every $T$ years. This work considered the $50 \mathrm{yr}$ return event. The $T$ year return event can be calculated from

$U_{T}= \begin{cases}u+\frac{\sigma}{\xi}\left[(\lambda T)^{\xi}-1\right], & \xi \neq 0 \\ u+\sigma \ln (\lambda T), & \xi=0 .\end{cases}$

In order to estimate the parameters of the GPD, the maximum likelihood method was used. Given that the values $y_{1}, y_{2}, \ldots, y_{n}$ are the $n$ excesses over the threshold $u$, the 
log-likelihood is given by

$L=\left\{\begin{array}{r}-n \ln \sigma-(1+1 / \xi) \sum_{i=1}^{n} \ln \left(1+\xi^{y_{i} / \sigma}\right), \quad \xi \neq 0 \\ -n \ln \sigma-1 / \sigma \sum_{i=1}^{n} y_{i}, \quad \xi \neq 0 .\end{array}\right.$

The log-likelihood cannot be analytically maximised, hence the Nelder-Mead simplex direct search algorithm was used to numerically minimise the negative log-likelihood with respect to the parameters of the GPD.

\section{Supplementary material related to this article is available online at: http://www.atmos-chem-phys.net/13/ 5163/2013/acp-13-5163-2013-supplement.pdf.}

Acknowledgements. This work was funded by Norwegian Research Council as part of the NRC project RECON 200610/S30, and by the Centre for Climate Dynamics at the Bjerknes Centre (SKD). The ENSEMBLES data used in this work was funded by the EU FP6 Integrated Project ENSEMBLES (Contract number 505539) whose support is gratefully acknowledged. The authors would also like to thank the reviewers and the editor for their suggestions which have helped improve this paper.

Edited by: W. Lahoz

\section{References}

Balkema, A. A. and de Hann, L.: Residual lifetime at great age, Annals of Prob., 2, 792-804, 1974.

Beniston, M.: The 2003 heat wave in Europe: a shape of things to come?, Geophys. Res. Lett., 31, L02202, doi:10.1029/2003GL018857, 2004.

Beniston, M., Stephenson, D. B., Christensen, O. B., Ferro, C. A. T., Frei, C., Goyette, S., Halsnaes, K., Holt, T., Jylha, K., Kofli, B., Palutikof, J., Scholl, R., Semmler, T., and Woth, K.: Future extreme events in European climate: an exploration of regional climate model projections, Climatic Change 81, 71-95, 2007.

Christensen, O. B., Drews, M., Christensen, J. H., Dethloff, K., Ketelsen, K., Hebestadt, I., and Rinke, A.: The HIRHAM Regional Climate Model Version 5 ( $\beta$ ), Tech Rep 06-17, ISSN 1399-1388, DMI, Copenhagen, 2006.

Coles, S.: An introduction to statistical modelling of extreme values, Springer, London, 208 pp., 2001.

Della-Marta, P. M., Mathis, H., Frei, C., Liniger, M., Kleinn, J., and Appenzeller, C.: The return period of wind storms over Europe, Int. J. Climatol., 29, 437-459, 2009.

Donat, M. G., Leckebusch, G. C., Wild, S., and Ulbrich, U.: Future changes in European winter storm losses and extreme wind speeds inferred from GCM and RCM multi-model simulations, Nat. Hazards Earth Syst. Sci., 11, 1351-1370, doi:10.5194/nhess-11-1351-2011, 2011a.
Donat, M. G., Renggli, D., Wild, S., Alexander, L. V., Leckebusch, G. C., and Ulbrich, U.: Reanalysis suggests long-term upward trends in European storminess since 1871, Geophys. Res. Lett., 38, L14703, doi:10.1029/2011GL047995, 2011b.

Fisher, R. A. and Tippett, L. H. C.: Limiting forms of the frequency distribution of the largest or smallest member of a sample, P. Camb. Philos. Soc., 24, 180-190, 1928.

Foley, A. M.: Uncertainty in regional climate modelling: A review, Prog. Phys. Geo., 34, 647-670, 2010.

Furevik, T., Bentesen, M., Drange, H., Kindem, I. K. T., and Kvamstø, N. G., and Sorteberg, A.: Description and evaluation of the Bergen climate model: ARPEGE coupled with MICOM, Clim. Dynam. 21, 27-51, 2003.

Grumm, R. H.: The central European and Russian heat event of July-August 2010, B. Am. Meteorol. Soc., 92, 1285-1296, 2011.

Gumbel, E. J.: Statistics of Extremes, Columbia University Press, New York, 1958.

Höglund, A., Meier, H. E. M., Broman, M., and Kriezi, E.: Validation and correction of regionalised ERA-40 wind fields over the Baltic Sea using the Rossby Centre Atmosphere model RCA3.0, Oceanographi. 97, SMHI, Stockholm, 2009.

Jones, R. N.: Managing uncertainty in climate change projections Issues for impact assessment - An editorial comment, Climatic Change, 45, 403-419, 2000.

Kharin, V. V., Zwiers, F. W., Zhang, X., and Hegerl, G. C.,: Changes in temperature and precipitation extremes in the IPCC ensemble of global coupled model simulations, J. Climate, 20, 1419-1444, 2007.

Koh, T.-Y., Djamil, Y. S., and Teo, C.-K.: Statistical dynamics of tropical wind in radiosonde data, Atmos. Chem. Phys., 11, 4177 4189, doi:10.5194/acp-11-4177-2011, 2011.

Kunz, M., Mohr, S., Rauthe, M., Lux, R., and Kottmeier, Ch.: Assessment of extreme wind speeds from Regional Climate Models - Part 1: Estimation of return values and their evaluation, Nat. Hazards Earth Syst. Sci., 10, 907-922, doi:10.5194/nhess10-907-2010, 2010.

Lagarias, J. C., Reeds, J. A., Wright, M. H., and Wright, P. E.: Convergence Properties of the Nelder-Mead Simplex Method in Low Dimensions, SIAM J. Optimiz., 9, 112-147, 1998.

Larsen, X. G. and Mann J.: The effects of disjunct sampling and averaging time on maximum mean wind speeds, J. Wind Eng. Ind. Aerod., 94, 581-602, 2006.

Lun, I. Y. F. and Lam, J. C.: A study of Weibull parameters using long-term wind observations, Renew. Energ., 20, 145-153, 2000.

Marsland, S. J., Haak, H., Jungclaus, J. H., Latif, M., and Röske, F.: The Max-Planck-Institute global ocean/sea ice model with orthogonal curvilinear coordinates, Ocean Model. 5, 91-127, 2003.

Munich Re: Topics GEO, Natural catastrophes 2011 analyses assessments positions, Munich Reinsurance Company Publications, Munich, 49 pp., 2011.

Naess, A. and Gaidai, O.: Estimation of extreme values from sampled time series, Struct. Saf., 31, 325-334, 2009.

Nakicenovic, N. and Swart, R. (Eds.): IPCC 2000, Emission Scenarios, Cambridge University Press, UK, 570 pp., 2000.

Nikulin, G., Kjellström, E., Hansson, U., Strandberg, G., and Ullerstig, A.: Evaluation and future projections of temperature, precipitation and wind extremes over Europe in an ensemble of regional climate simulations, Tellus A, 63, 41-55, 2011. 
Outten, S. D., Renfrew, I. A., and Petersen G. N.: An easterly tip jet off Cape Farewell, Greenland. Part II: simulations and dynamics, Q. J. Roy. Meteor. Soc., 135, 1934-1949, 2009.

Palutikof, J. P., Brabson, B. B., Lister D. H., and Adcock, S. T.: A review of methods to calculate extreme wind speeds, Meteorol. Appl., 6, 119-132, doi:10.1017/S1350482799001103, 1999.

Perrin, O., Rootzen, H., and Taesler, R.: A discussion of statistical methods used to estimate extreme wind speeds, Theor. Appl. Climatol. 85, 203-215, 2006.

Pickands, J.: Statistical inference using extreme order statistics, Ann. Stat., 3, 119-131, 1975.

Pryor, S. C., Barthelmie, R. J., Clausen, N. E., Drews, M., MacKellar, N., and Kjellström, E.: Analyses of possible changes in intense and extreme wind speeds over Northern Europe under climate change scenarios, Clim. Dynam. 38, 189-208, 2012a.

Pryor, S. C., Nikulin, G., and Jones, C.: Influence of sptial resolution on regional climate model derived wind climates, J. Geophys. Res., 117, D03117, doi:10.1029/2011JD016822, 2012b.

Quine, C. P.: Estimation of mean wind climate and probability of strong winds for wind risk assessment, Forestry, 73, 247-258, 2000.

Renfrew, I. A., Outten, S. D., and Moore, G. W. K.: An easterly tip jet off Cape Farewell, Greenland. Part I: Aircraft observations, Q. J. Roy. Meteor. Soc., 135, 1919-1933, 2009.

Robine, J. M., Cheung, S. L. K., Sophie, L. R., Oyen, H. V., Griffiths, C., Michel, J. P., and Hermann, F. R.: Death toll exceeded 70,000 in Europe during the summer of 2003, C. R. Biol., 331, 171-178, 2008.

Rockel, B. and Woth, K.: Extremes of near-surface wind speed over Europe and their future changes as estimated from an ensemble of RCM simulations, Climatic Change, 81, 267-280, 2007.

Roeckner, E., Bäuml, G., Bonaventura, L., Brokopf, R., Esch, M., Giorgetta, M., Hagemann, S., Kirchner, I., Kornblueh, L., Manzini, E., Rhodin, A., Schlese, U., Schulzweida, U., and Tompkins, A.: The atmospheric general circulation model ECHAM5. Part I: Model description, MPI-Report, 349, 1-127, 2003.

Rummukainen, M.: State-of-the-art with regional climate models, Wiley Interdisciplinary Rev., Climatic Change, 1, 82-96, 2010.
Samuelsson, P., Jones, C., Willén, U., Gollvik, S., Hansson, U., Kjellström, E., Nikulin, G., Ullerstig, A., and Wyser, K.: The Rossby Centre regional climate model RCA3: model description and performance, Tellus A, 63, 4-23, doi:10.1111/j/16000870.2010.00478.x, 2011.

Schwierz, C., Kollner-Heck, P., Mutter, E., Bresch, D., Vidale, P., Wild, M., and Schär, C.: Modelling European winter wind storm losses in current and future climate, Climatic Change 101, 485514, 2010.

Smith, R. B.: Synoptic observations and theory of orographically disturbed wind and pressure, J. Atmos. Sci. 39, 60-70, 1982.

Solomon, S., Qin, D., Manning, M., Chen, Z., Marquis, M., Averyt, K. B., Tignor, M., and Miller, H. L. (Eds.): Contribution of Working Group I to the Fourth Assessment Report of the Intergovernmental Panel on Climate Change, Cambridge University Press, Cambridge, UK and New York, NY, USA, 996 pp., 2007.

Van de Vyver, H. and Delcloo, A. W.: Stable estimations for extreme wind speeds. An application to Belgium, Theor. Appl. Climatol. 105, 417-429, doi:10.1007/s00704-010-0365-9, 2011.

Van den Eynde, D., De Sutter, R., and Haerens, P.: Evolution of marine storminess in the Belgian part of the North Sea, Nat. Hazards Earth Syst. Sci., 12, 305-312, doi:10.5194/nhess-12-305-2012, 2012.

van der Linden, P. and Mitchell, J. F. B. (Eds.): ENSEMBLES: Climate Change and its Impacts: Summary of research and results from the ENSEMBLES project, Met Office Hadley Centre, FitzRoy Road, Exeter EX1 3PB, UK, 160 pp., 2009.

Wang, X. L., Wan, H., Zwiers, F. W., Swail, V. R., Compo, G. P., Allan, R. J., Vose, R. S., Jourdain, S., and Yin, X.: Trends and lowfrequency variability of storminess over western Europe 18782007, Clim. Dynam. 37, 2355-2371, 2011.

WMO: Cold spell in Europe and Asia in late winter 2011/2012 2012, https://www.wmo.int/pages/mediacentre/ news/documents/dwd_2012_report.pdf, (last access: 10 January 2013), 2012.

Zwiers, F. W. and V. Kharin V. V.: Changes in the extremes of the climate simulated by CCC GCM2 under $\mathrm{CO}_{2}$ doubling, J. Climate, 11, 2200-2222, 1998. 